Issues in Information Systems

Volume 18, Issue 4, pp. 1-8, 2017

\title{
WHY IS WECHAT PAY SO POPULAR?
}

\author{
Jianfeng Wang, Indiana University of Pennsylvania,jwang@iup.edu \\ Linwu Gu, Indiana University of Pennsylvania, lgu@iup.edu
}

\begin{abstract}
Mobile wallets have grown very quickly in China in the past few years. The market value of mobile wallet is tremendously increasing. By integratinging the social theory and extended acceptance model (TAM), this study develops a model to identify perceived social influence, perceived networking ability, and investigate their effects on the perceived convenience of relationship maintenance, and subsequently how the intention to use WeChat is shaped up. Data were collected from 122 WeChat users to test our model. The analytical results are very supportive.
\end{abstract}

Keywords: Mobile Wallet, WeChat Pay, Social factors

\section{INTRODUCTION}

More than 1 million U.S stores accept Samsung Pay, Apple Pay, and Android Pay. In China, AliPay and WeChat Pay are both very popular. They grew from nothing to popular payment approaches in just a few years. According to Forbes report in 2017, AliPay market share is about 54\% in mobile transaction processing while WeChat Pay enjoyed $40 \%$ of transaction processing (Luk, 2017). AliPay is a dominating payment method in Alibaba ecommerce platform T-Mall and Taobao. Alibaba does not allow WeChat Pay to be used there. We are more interested in WeChat Pay as its growth and becoming popularity is based on Tencent social media application, WeChat. WeChat is the top social chat tool with about 1 billion active users in China and other parts of the World. In this paper, we examine WeChat Pay's peer to peer mobile payment. The question of what factors contribute to user intention to use WeChat Pay is important. It is significant for researchers to find factors of perceived usefulness of peer to peer mobile wallet and understand its contributions to shaping up user perceptions of, and intention to use WeChat Pay. WeChat Pay users need to bind a bank account with the social media app, WeChat from Tencent. Users can use WeChat Pay to pay via QR Code, Quick Pay, In-App Web-Based or Native in-App Payments. We will not discuss the detail here in the paper. Readers can visit https://pay.weixin.qq.com/index.php/public/wechatpay for the very details of how to set up WeChat Pay in a smart phone.

This study develops a model to see how users accept peer to peer mobile wallet (WeChat Pay) based on the social theory and technology acceptance model (TAM) (Davis, 1989). Social exchange theory explains how different social factors impact a person's behavior when he/she creates and maintains a relationship (Blau 1964; Hsu and Lu 2004). Perceived social influence can perceive social impacts and produce reciprocating interactions. It is social influence that results in word of mouth marketing $(\mathrm{Ng}, 2013)$. Moreover, previous research indicates that networking is the determinant of maintenance of interpersonal relationships (de Janasz \& Forret, 2008). However, the perceived threat of device loss or theft may discourage the use of mobile application (Tu et al., 2005). The next section of this paper presents the theoretical background of this research. The third section reviews the literature of social theories and TAM model. We develop a research model (Figure 1) and propose relevant research hypotheses, the research methodology. At the end, we present the research findings, the theoretical contributions, and the limitations of the study. 


\section{THEORY FOUNDATION}

\section{Social theories}

Social exchange theory explains interpersonal interactions from a cost-benefit perspective (Blau, 1964). The social exchange value suggests that perceived networking ability is particularly important for creating social connection. Informational social influences and factors are especially significant to users' perceptions on online social network system (Ng 2013; Tu et al. 2015; Hsu et al. 2004). The common thread of social factors in social networking deals with social relations, and the impersonal configuration of relationships to a behavior (Nov et al. 2012; Nahapiet \& Ghoshal 1998; Gu \& Wang 2014).

\section{Extended Technology Acceptance Model}

Lots of previous studies applied TAM (Davis, 1989) to predict the user acceptance affected by external variables such as social influences and system accessibility (Husu \& Lu 2004; Lin \& Lu 2000). The extended model of TAM has been empirically validated, and is widely used for predicting the user intention in information technology research (Venkatesh \& Davis, 2000).

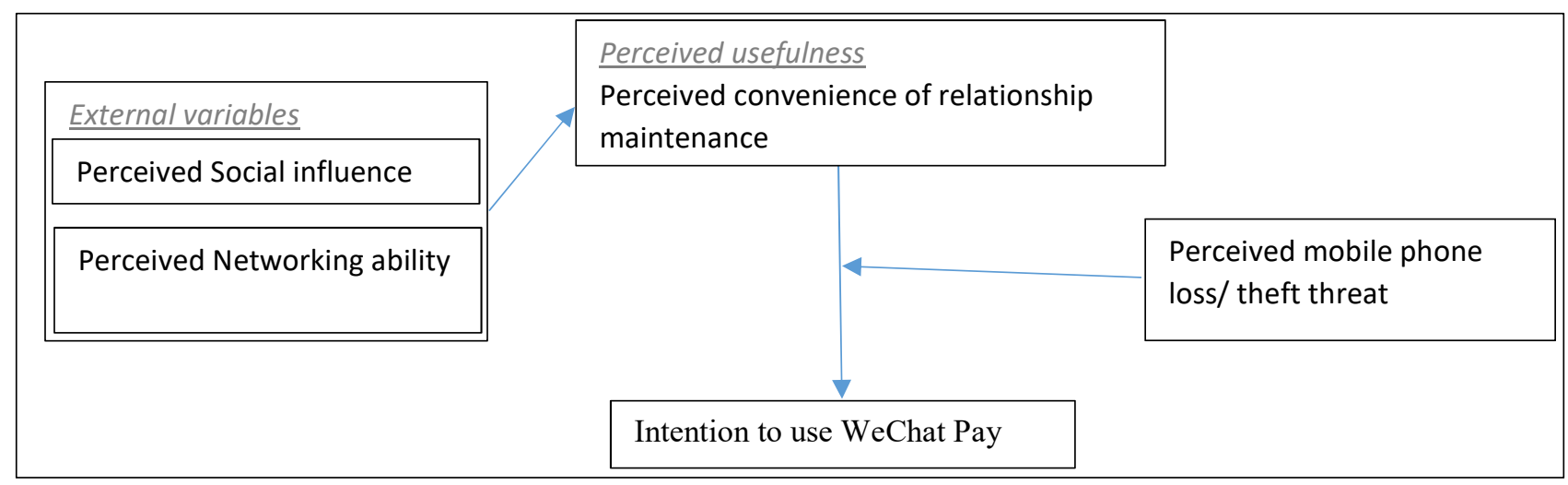

Figure 1. Research Model of Social factor on an Online Social Network System

\section{RESEARCH MODEL AND HYPOTHESES}

\section{Perceived Social Influence, Perceived Networking Ability, and Perceived Convenience of Relationship Maintenance}

Social influence is defined as a condition in which a person accepts and agrees with another's belief and behavior. It is particularly important for creating social relationship (Balaji et al. 2016; Kelman 1958; Ng 2013; Janasz \& Forret 2008). Perceived networking ability refers to user awareness of the networking value to build relationships (Matook 2015; Jean et al. 2014). Social networking ability has been widely proved valuable because social networking connections impact users' similar behaviors through a word-of-mouth influence (Hazleton \& Kennan 2005; Wang et al. 2013; Liu et al. 2016). Previous research also finds that the social networking connection is a significant predictor of behavioral intentions (Ellison et al., 2007)

According to the reviews above, we propose:

H1: Perceived social influence positively affects perceived convenience of relationship maintenance.

H2: Perceived networking ability positively affects perceived convenience of relationship maintenance.

H3: Perceived convenience of relationship maintenance positively affects intention to use WeChat Pay 


\section{Perceived Threat of Mobile Device Loss or Theft, and Intention to Use WeChat Pay}

WeChat Pay makes cashless transaction possible without the use of a physical card. However, the owner would be worried on the mobile wallet when a mobile device is lost or stolen. Perceived threat refers to user awareness of loss or theft of mobile device. The perceived threat decreases person's intention to use (Tu et al., 2015).

We propose:

H4: Perceived threat moderates the relationship between perceived convenience of relationship maintenance and intention to use WeChat Pay.

\section{RESEARCH METHODOLOGY}

\section{Measures}

In order to test the proposed hypotheses, we used measurement items found in related studies and modify them for the measures in this research. The scales and the questionnaire for the proposed hypotheses are shown in Appendix. All the measures use seven-point Likert scales, from 1=strongly disagree to $7=$ strongly disagree.

Table 1. Sample Demographics

\begin{tabular}{|l|l|l|l|}
\hline \multicolumn{1}{|c|}{ Demographics } & \multicolumn{1}{|c|}{ Category } & Returned samples & \multicolumn{1}{c|}{ percent } \\
\hline Gender & male & 68 & $55.74 \%$ \\
\hline & Female & 54 & $44.26 \%$ \\
\hline Age & $18-25$ & 33 & $27.0 \%$ \\
\hline & $25-35$ & 26 & $21.3 \%$ \\
\hline & $35-45$ & 28 & $23.0 \%$ \\
\hline Education & Above 45 & 35 & $28.7 \%$ \\
\hline & College & 52 & $42.62 \%$ \\
\hline Occupation & Graduate or above & 70 & 57.38 \\
\hline & student & 39 & $31.97 \%$ \\
\hline & Working & 80 & $65.57 \%$ \\
\hline The types of mobile phone & unemployed & 3 & $2.46 \%$ \\
& Apple & 97 & $75.41 \%$ \\
& others & 25 & $24.59 \%$ \\
\hline
\end{tabular}

\section{Subjects and Procedures}

Our research focuses on WeChat Pay, a mobile payment solution completely integrated in the social media application. There are about 1 billion WeChat users, of which more than 70 million use WeChat outside of China. First, we designed the survey questionnaires on the shared google document, and posted the link in WeChat groups we joined. All group members are Chinese American residents or Chinese students studying in the U.S. These WeChat groups have the number of members ranging from 56 to 500. We only know some group members there. We don't know most of the group members. We contacted the group leaders for their approval of posting the survey link in their groups. WeChat allows the users to send WeChat red envelopes (hongbao) with lucky money to group members. In order to encourage people to do the survey, we sent red envelopes with topic "Grab your lucky money, and do the survey, please." to each group. We put certain amount of RMBs in a digital red envelope and set it randomly, so people have chances to get lucky money at a random amount during the available period of time. After we sent the red envelope, everyone in the group could see the red envelope icon and link. Group members grab and open it as fast as possible so that they can receive a portion of the red envelope. For example, our red envelope of $100 \mathrm{RMB}$ was shared by 22 people in one group within 53 minutes. The largest red envelope with lucky money was $8.48 \mathrm{RMB}$, and the smallest envelope only contained $0.05 \mathrm{RMB}$. We chose WeChat Pay because of its popularity and ease of use. WeChat users enjoy to grab lucky money for fun. Finally, we received 122 responses. Participants had used smart phones for 5.9 years and used WeChat for 3.1 years on average. Table 1 shows the demographic statistics of the samples (Table $1)$. 


\section{Issues in Information Systems}

Volume 18, Issue 4, pp. 1-8, 2017

\section{RESULTS}

We used confirmatory factor analysis to test the measurement model. Convergent validity and discriminant validity are used to test the constructs of the research model. As shown in Table 2, the composite reliability of all the constructs is above 0.7 , and AVE is above 0.5 , which are all beyond their corresponding thresholds. Table 3 demonstrates the discriminant validity. The square roots of AVE are higher than the levels of correlations involving the construct.

Table 2. Descriptive Results and Internal Consistency of Model Constructs

\begin{tabular}{|l|l|l|l|l|l|l|}
\hline $\begin{array}{c}\text { Construct } \\
\text { items }\end{array}$ & $\begin{array}{c}\text { No. of } \\
\text { items }\end{array}$ & Means & $\begin{array}{c}\text { Standard } \\
\text { deviation }\end{array}$ & $\begin{array}{c}\text { Composite } \\
\text { reliability }\end{array}$ & AVE & $\begin{array}{c}\text { AVE square } \\
\text { root }\end{array}$ \\
\hline PSI & 4 & 4.6 & 1.1 & 0.80 & 0.77 & 0.88 \\
\hline PNA & 3 & 5.7 & 0.8 & 0.88 & 0.66 & 0.81 \\
\hline PCRM & 4 & 4.3 & 0.9 & 0.83 & 0.76 & 0.87 \\
\hline PT & 3 & 5.6 & 1.1 & 0.75 & 0.83 & 0.91 \\
\hline ITUW & 3 & 4.9 & 1.3 & 0.71 & 0.85 & 0.92 \\
\hline
\end{tabular}

*Variables: Perceived social influence (PSI), Perceived Networking Ability (PNA), Perceived convenience of relationship maintenance (PCRM), Perceived threat (PT), and Intention to use WeChat pay (ITUW).

Table 3. Square Root of AVE and Cross-correlations

\begin{tabular}{|l|l|l|l|l|l|}
\hline & \multicolumn{1}{|c|}{ PSI } & \multicolumn{1}{c|}{ PNA } & PCRM & PT & IUW \\
\hline PSI & 0.877 & & & & \\
\hline PNA & 0.443 & 0.812 & & & \\
\hline PCRM & 0.673 & 0.269 & 0.871 & & \\
\hline PT & 0.453 & 0.534 & 0.521 & 0.911 & \\
\hline ITUW & 0.232 & 0.512 & 0.244 & 0.384 & 0.922 \\
\hline
\end{tabular}

*Variables: Perceived social influence (PSI) Perceived Networking Ability (PNA),

Perceived convenience of relationship maintenance (PCRM), Perceived threat (PT), and Intention to use WeChat pay (ITUW).

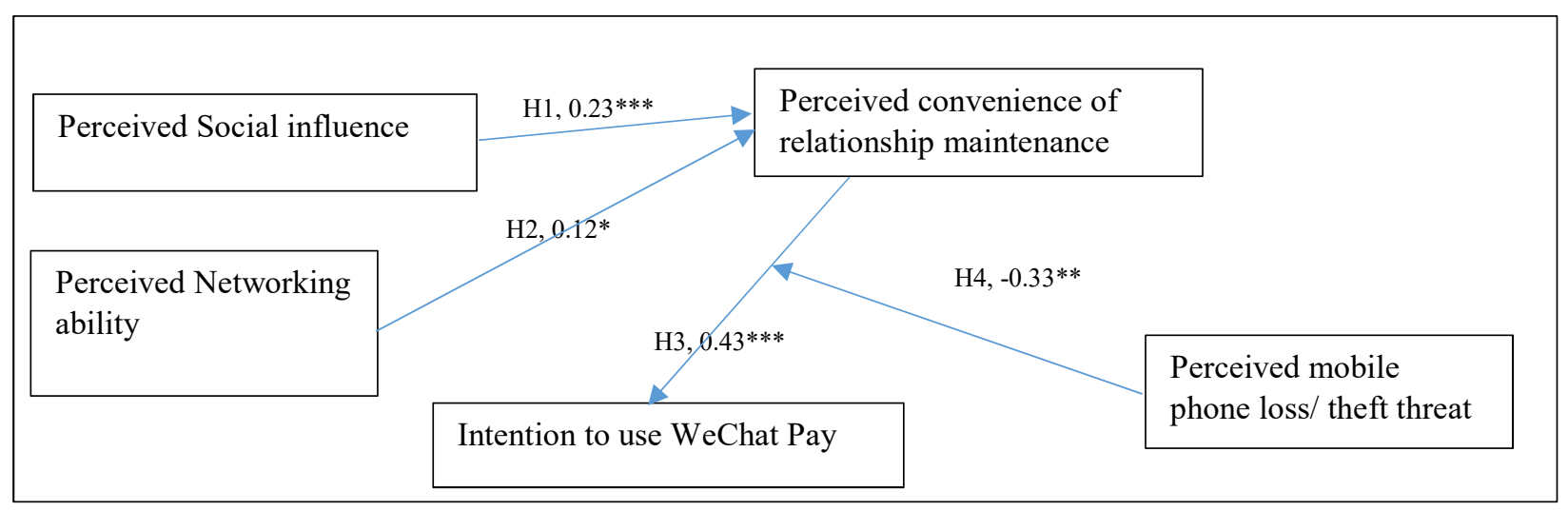

Figure 2. The Analytical Results $\left({ }^{*} \mathrm{p}<0.05, * * \mathrm{p}<0.01,{ }^{* * *} \mathrm{p}<0.001\right)$ 
Table 4. Hypothesis Testing Results

\begin{tabular}{|l|l|l|l|l|}
\hline & \multicolumn{1}{|c|}{ Path } & Coefficient & P-value & \multicolumn{1}{|c|}{$\begin{array}{c}\text { Supported } \\
\text { /Rejected }\end{array}$} \\
\hline $\mathrm{H}_{1}$ & $\begin{array}{l}\text { Perceived social influence->perceived } \\
\text { convenience of relationship maintenance }\end{array}$ & 0.231 & 0.000 & Supported \\
\hline $\mathrm{H}_{2}$ & $\begin{array}{l}\text { Perceived network ability->perceived } \\
\text { convenience of relationship maintenance }\end{array}$ & 0.124 & 0.021 & Supported \\
\hline $\mathrm{H}_{3}$ & $\begin{array}{l}\text { perceived convenience of relationship } \\
\text { maintenance ->intention use to WeChat } \\
\text { Pay }\end{array}$ & 0.426 & 0.000 & Supported \\
\hline $\mathrm{H}_{4}$ & $\begin{array}{l}\text { Perceived threat moderate the relationship } \\
\text { between convenience of relationship } \\
\text { maintenance and intention use to WeChat } \\
\text { Pay }\end{array}$ & -0.327 & 0.003 & Supported \\
\hline
\end{tabular}

\section{Structural Analyses}

The structural analysis using PLS was conducted. We first tested the main effects of social influence and perceived networking ability on the perceived convenience of relationship maintenance. We then tested the moderating effects of perceived threat on the causal relationships between the perceived convenience of relationship maintenance and intention to use WeChat pay. Table 4 shows that the full model is significant, with $\mathrm{F}=18.39, \mathrm{p}<0.001$, and adjusted $\mathrm{R}_{2}=58.3 \%$. The results show that two antecedent factors - perceived social influence, and perceived networking ability significantly affect perceived convenience of relationship maintenance. In addition, the perceived threat is added to the model to examine the moderation effect. The result indicates that perceived threat moderates the causal relationships between the perceived convenience of relationship maintenance and intention to use WeChat Pay (Figure 2).

\section{DISCUSSION AND CONCLUSIONS}

Although several studies previously examined the effect of social factors on IS success, less research was done to understand the role of social factors in motivating users to use mobile wallets. WeChat Pay is a good case for us to look at in understanding social factors on IS success because WeChat Pay is a built-in function with WeChat and its growth and popularity is associated with the social media tool, WeChat. Our study shows that social factors play an important role in using peer to peer mobile payment systems. Our major findings show that social influence and networking ability help users feel that they are supported and help them use mobile wallets. WeChat is such a dominating social chat tool that Tencent is able to try many options to engage WeChat users to tie their bank accounts with WeChat Pay. One quite successful one is red envelope (hongbao), which has been deeply rooted in China as a way of gift in holidays.

The success of AliPay lies in the fact that Alibaba does not allow the use of WeChat Pay in T-Mall and Taobao.com for transaction processing. The paths to success for WeChat Pay and Ali Pay are certainly very different. The success of WeChat Pay attributes a lot to that of WeChat, a social chat tool. We don't think we should compare PayPal with WeChat Pay in this research because their histroies are very different. PayPal, first used in Ebay.com, has slowly gained its popularity in many years. WeChat Pay is basically a mobile payment approach. PayPal s not rooted in any mobile platform.

There are several limitations to our study. First, most subjects use Apple smart phones. We did not consider situational factors such as how different models and brands of mobile devices might affect different their owner perceptions. Second, even though the results are consistent with our theoretical assumptions, the cross-sectional design could not completely rule out alternative results. Third, the study was limited in terms of its use of intention as the dependent variable. Fourth, The subject users in this research are all Chinese. 


\section{Issues in Information Systems \\ Volume 18, Issue 4, pp. 1-8, 2017}

The business implication is very significant from our research. WeChat Pay can be very effective way of reaching Chinese customers such as Chinese tourists. Investigating the factors that influence individuals' intention to use WeChat Pay is of fundamental interest to business. It is significant for developers, service providers, and marketers to find determinants of peer to peer mobile wallet and understand its contributions to shaping up user perceptions.

\section{REFERENCES}

Blau, P. (1964). Exchange and power in Social Life, Wiley, New York.

Balaji, M. S., Khong, K. W, Yee, A., \& Chong, Loong (2016). Determinants of negative word-of-mouth communication using social networking sites. Information \& Management, 53(4), 528-540.

Davis, F. D. (1989). Perceived usefulness, perceived ease of use, and user acceptance of information technology, MIS Quarterly, 13(3), 319-339.

de Janasz, S. C., \& Forret, M. L. (2008). Learning the art of networking: A critical skill for enhancing social capital and career success. Journal of Management Education, 32(5), 629-650.

Ellison, N. B. Steinfield, C. \& Lampe, C. (2007). The benefits of Facebook "friends": social capital and college students' use of online social network sites, Journal Computer-Mediated. Communication, 12(4), 11431168 .

Gu, L. \& Wang, J. (2014). How does social capital influence an online social network system. Issues in Information System, 15(1), 217-223.

Hazleton, V. \& Kennan, W. (2000). Social capital: Reconceptualizing the bottom line, Corporate Communication: An International Journal, 5(2), 81-86.

Hsu, C. \& Lu, H. (2004). Why do people play on-line games? An extended TAM with social influences and flow experience. Information \& Management, 41(7), 853-868

Hsu, C. \& Lin, J. (2008). Acceptance of blog usage: The roles of technology acceptance, social influence and knowledge sharing motivation. Information \& Management, 45(1), 65-74

Jean, R. 1., Sinkovics, R. R. , \& Kim, D. (2014). The impact of technological, organizational and environmental characteristics on electronic collaboration and relationship performance in international customer-supplier relationships. Information \& Management, 51(7), 854-864.

Kelman, H.C. (1958). Compliance, identification, and internalization: three processes of attitude change. Journal of Conflict Resolution, 2(1), 51-60.

Kwon, S. J., Parka, E., \& Kim, K. J. (2014). What drives successful social networking services? A comparative analysis of user acceptance of Facebook and Twitter. The Social Science Journal 51(4), 534-544.

Lin, J. \& Lu, H. (2000). Toward an understand of the behavioral intention to use a web site. International Journal of Information Management, 20(3), 197-208.

Liu, Z., Min, Q., Zhai, Q., \& Smyth, R. (2016). Self-disclosure in Chinese micro-blogging: A social exchange theory perspective. Information \& Management, 53(1), 53-63.

Lu, H., Hsiao, K. (2010). The influence of extro/introversion on the intention to pay for social networking sites. Information \& Management, 47(3), 150-157. 


\section{Issues in Information Systems}

Volume 18, Issue 4, pp. 1-8, 2017

Luk, G. (2017). Is WeChat Pay taking over AliPay? https://www.forbes.com/sites/quora/2017/06/20/is-wechat-paytaking-over-alipay/\#3369428d3a0b, retrieved on June 24, 2017.

Matook, S, Cummings,J. \& HillolL, B. (2015). Are You Feeling Lonely? The Impact of Relationship Characteristics and Online Social Network Features on Loneliness. Journal of Management Information Systems, 31(4), 278-310.

Nahapiet, J., \& Ghoshal, S. (1998). Social capital, intellectual capital, and the organizational acbantage. Academy of Management Review. 23(2), 242-266.

Ng, C. (2013). Intention to purchase on social commerce websites across cultures: A cross-regional study. Information \& Management, 50(8), 609-620.

Nov, O., Ye, C., \& Kumar, N. (2012). A social capital perspective on meta-knowledge contribution and social computing. Decision Support Systems, 53(1), 118-126

Tu, Z. Turel,O, Yuan,Y., and Archer, N. (2015). Learning to cope with information security risks regarding mobile device loss or theft: An empirical examination. Information \& Management, 52(4), 506-517.

Venkatesh V. \& Davis, F.D. (2000). A theoretical extension of the technology acceptance model: four longitudinal field studies, Management Science, 46(2), 186-204.

Wang. Y, Meister, D.B., \& Gray, P. (2013). Social Influence and Knowledge Management Systems Use. MIS Quarterly, 37(1), 299-313. 


\section{Issues in Information Systems}

Volume 18, Issue 4, pp. 1-8, 2017

\section{APPENDIX}

1. Social influence (adapted from Barnes and Bidgen, 2012)

SI1 People who influence my behavior think that I should use this

SI2 People who are important to me think I should use this

SI3 People who are my friends think I should use this

SI4 People who are my family members think I should use this

2. Perceived Networking ability (modified from Matook et al., 2015)

PNA1 I spend a lot of time developing connections with others.

PNA 2 I know a lot of people and am well connected.

PNA3 I am good at building relationships with people.

3. Convenience of relationship maintenance (adapted from Liu et al., 2016)

CRM1 WeChat Pay is convenient for any payments between individuals.

CRM2 WeChat Pay allows me to save time when I want to pay something to my friends/family.

CRM3 I find WeChat Pay efficient to pay back to my friends/family.

CRM4 I find WeChat Pay efficient to receive cash from my friends/family.

Perceived threat (modified from Tu et al., 2015)

PT1 There is a good possibility that my mobile device would be lost or stolen It is likely that the data stored in my lost or stolen mobile device will be lost

PT2 It is likely that I will lose access to services through my lost or stolen mobile device.

PT3 My lost or stolen mobile devices would cause significant financial loss

Intention to use (adapted from Kwon et al., 2014)

IU1: I will continue to use WeChat Pay

IU2: I will recommend my friends to use WeChat Pay.

IU3: I intend to use WeChat Pay as much as possible. 